\title{
PARK KRALJA PETRA KREŠIMIRA IV. U ZAGREBU - DRVENASTE BILJKE
}

\author{
KRALJ PETAR KREŠIMIR IV. PARK IN ZAGREB - WOODY \\ PLANTS
}

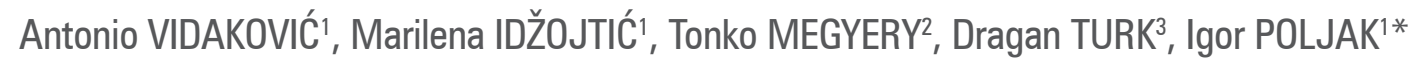

\begin{abstract}
SAŽETAK
Park kralja Petra Krešimira IV. u Zagrebu spomenik je parkovne arhitekture i jedan od povijesno važnih, starih parkova u gradu Zagrebu. Radi utvrđivanja sadašnjega stanja drvenastih biljaka u parku, napravljena je dendrološka analiza te je učinjena usporedba sadašnjega stanja dendroflore sa stanjem iz 1962. i 1995. godine. Biljke su determinirane u razdoblju od ljeta 2018. do ljeta 2019. godine, a u radu su analizirani sljedeći podaci: brojnost pojedinih svojti (vrsta, podvrsta, varijeteta, križanaca i kultivara), pripadnost porodici, areal, habitus, trajnost listova, boja cvjetova, vrijeme cvjetanja, plodovi te broj autohtonih i alohtonih svojti. Ukupno su zabilježene 122 svojte raspoređene unutar 36 porodica. Od toga sedam svojti pripada golosjemenjačama, a ostalo su kritosjemenjače. Broj svojti se povećao za 29 u odnosu na 1995. godinu, kada ih je bilo 93, odnosno za 44 u odnosu na 1962. godinu, kada ih je bilo 78. Danas, 40 od navedenih 93 svojte iz 1995. godine više nije prisutno u parku, kao ni 40 svojti zabilježenih 1962. godine. Autohtonih svojti je 28, a od alohtonih najviše je azijskih i sjevernoameričkih. Kao posebno vrijedni primjerci starog, velikog drveća svojom pojavom ističu se stabla ginka, hibridnih platana, virdžinijskoga draguna i mandžurskoga plutnjaka, koja su u parku od njegova osnutka i čine važan dio njegova vizualnog identiteta.
\end{abstract}

KLJUČNE RIJEČl: dendroflora, dendrološka analiza, drveće i grmlje, hortikultura, urbano zelenilo

\section{UVOD}

\section{INTRODUCTION}

Danas se više nego ikad ističe važnost zelenih površina u gradskim sredinama. Njima se nastoji razbiti gradska monotonija te pružiti stanovnicima doticaj s prirodom i poboljšati njihovu kvalitetu života. Zelenilo je osnovni element identiteta jednoga grada, gdje ono osim estetske ima i niz drugih uloga, kao što su pročišćavanje zraka, zaštita od buke i prašine, ublažavanje temperaturnih ekstrema, zadržavanje vlage, očuvanje bioraznolikosti, sprečavanje erozije tla i mnoge druge. Osim toga, zelene površine imaju i pozitivan utjecaj na psihofizičko zdravlje ljudi, jer su često korištene i u rekreativne svrhe.

Kroz stoljeća, u Zagrebu su sustavno nastajali perivojnopejzažni prostori koji su se širili s gradom. Krajem 18. i početkom 19. stoljeća nastaju prvi veliki perivoji, Maksimir i Ribnjak (koji otvara svoja vrata javnosti tek 1946. godine), koji su do današnjega dana zadržali svoju funkciju i osebujnost (Sopina i sur. 2013). Osim njih, za Zagrepčane i njihove goste od posebnoga su značaja i sedam parkova i botanički vrt koji su dio takozvane Zelene ili Lenuzzijeve potkove.

\footnotetext{
'Antonio Vidaković, mag. ing. silv., prof. dr. sc. Marilena Idžojtić, doc. dr. sc. Igor Poljak, Sveučilište u Zagrebu, Šumarski fakultet, Zavod za šumarsku genetiku, dendrologiju i botaniku, Svetošimunska cesta 23, 10000 Zagreb

${ }^{2}$ Tonko Megyery, prvostupnik urbanoga šumarstva, zaštite prirode i okoliša, student diplomskoga studija Urbano šumarstvo, zaštita prirode i okoliša

${ }^{3}$ Dragan Turk, mag. ing. silv. spec. univ. silv., Javna ustanova Nacionalni park Risnjak, Bijela Vodica 48, 51317 Crni Lug

Korespondencija: doc. dr. sc. Igor Poljak, ipoljak@sumfak.hr
} 
U međuratnom razdoblju nisu zabilježeni veći perivojnopejsažni pothvati, već samo interpolacija unutar donjogradske blokovske matrice, gdje se integriraju Trg kralja Petra Krešimira IV. i Trg žrtava fašizma (Sopina i sur. 2013). Početkom 20. stoljeća započinje plansko širenje grada na istok. Određivanje i planiranje novih urbanih i prometnih prostora rađeno je prema modelu prethodnoga stoljeća, pri čemu je potez reguliranog toka potoka Medveščak služio kao ishodište prepoznatljive strukture novoga istočnoga dijela grada, duž kojega je formiran Trg kralja Petra Krešimira IV. Time je taj, do tada rubni, sajmišni prostor grada poprimio karakter trga-parka, prometnoga čvorišta i prepoznatljivog elementa širega gradskoga prostora (Barišić 2002). Njegov karakter prometnoga čvorišta određen je njegovom velikom površinom is čak deset prometnica koje prolaze njegovim područjem.

Tijekom stoljeća, taj još nedefiniran prostor postupno se oblikuje izgradnjom stambenih $\mathrm{i}$ javnih zgrada. Prve stambene zgrade realizirane su s istočne strane Trga, gdje je od 1923. do 1926. izgrađena stambeno-uredska zgrada "Činovnički dom", djelo arhitekta Valeriana Riesznera, koja je svojom velikom dimenzijom predočavala ambiciozno mjerilo toga novoga gradskoga prostora. Već sljedeće godine započinje definiranje i zapadnoga ruba Trga gradnjom sjeverne uglovnice arhitekata Slavka Benedika i Aladana Baranyaia te niza stambenih zgrada. Uz sjeverne radijalne prometnice, početkom 30-ih godina realizirane su dvije specifične trostrane uglovnice koje su bočno definirale još neizgrađenu parcelu sjeverne strane budućega Trga. Južni niz stambenih zgrada realiziran je nakon uređenja parka 1937. godine, a konačnu definiciju Trgu dala je nova, široka i reprezentativna prometnica u smjeru jugoistoka (danas Ulica kneza Višeslava), koja je presijecala dotada još u potpunosti nedefiniran prostor Trga (Barišić 2002).

Svjestan važnosti i značaja ovog novog gradskog prostora, danas poznatog kao Trg kralja Petra Krešimira IV., grad Zagreb za njegovo uređenje raspisuje prvi parkovni natječaj u Kraljevini Jugoslaviji na kojemu je prvonagrađeni projekt pejsažnoga slovenskoga arhitekta Cirila Jegliča realiziran 1937.-1938. godine. Bio je to prvi moderni gradski park u zemlji, koji je za razliku od do tada karakterističnoga dekorativno-reprezentativnoga uređenja parkovnih prostora imao izrazito naglašenu socijalnu namjenu. Projektant je iskoristio negativan čimbenik presijecanja parka prometnicom kako bi napravio park s dvije različite cjeline. Južni dio parka osmišljen je kao "prirodnije" oblikovan prostor kojim dominira središnja livada omeđena krošnjama i zavojitim stazama. Sjeverna, manja cjelina podijeljena je na tri dijela: cvjetni vrt za odrasle, središnji parterni vrt i dječje igralište, prvo takvo u Hrvatskoj (Barišić 2002).

Zbog svoje lokacije i atraktivnosti, park nakon Drugoga svjetskog rata postupno gubi svoju cjelovitost i funkciju. Okolne zgrade se prenamjenjuju i stvaraju se novi prometni pravci prema jugu, čime se gubi ciljana skupina korisnika parka. Daljnjom urbanizacijom ovaj park prerasta iz rubnog područja u pravo gradsko čvorište, zbog čega djelomično gubi i svoj meditativni karakter. Zbog toga, ali i zbog slabog održavanja i onečišćenja, do sada su provedena tri projekta obnove. Prvi je vodila arhitektica Mira Halambek-Wenzler 1979. godine, u kojemu je osim obnove bio predviđen i redizajn pojedinih dijelova, obogaćivanje vegetacije i inventara, ali i redukcija pojedinih elemenata. Međutim, projekt je tek djelomično realiziran. Istu sudbinu doživio je i projekt obnove i sanacije iz 1991. godine. Ubrzo nakon toga, 1997. godine, slijedi rekonstrukcija povijesnih vrijednosti, odnosno obnova staza, redizajn pojedinih elemenata, obnova vegetacije i inventara te dječjeg igrališta. Posljednji projekt obnove i revitalizacije proveden je 2016. godine. Tada je napravljena replika fontane "Kozmički ciklus vode", posađene su nove biljke, obnovljene su kamene staze, postavljene su nove klupe i koševi za smeće. Obnovljen je i bazen i donji dio fontane te je postavljena nova pergola i rasvjetni stupovi s fenjerima. Park kralja Petra Krešimira IV., koji se nalazi na istoimenom trgu u Zagrebu, 2000. godine proglašen je spomenikom parkovne arhitekture i upisan u Upisnik zaštićenih dijelova prirode koji vodi Ministarstvo zaštite okoliša i energetike. Površina parka je 2,4 ha.

Danas, kada su biljke već u potpunosti razvijene, park pruža utočište i bijeg od gradskog sivila i užurbanosti, što je dokaz njegove uspješne borbe s urbanizacijom i modernizacijom grada Zagreba. Svjesni njegove povijesne, kulturološke i dendrološke važnosti, odlučili smo ovom pomalo zanemarenom parku posvetiti pažnju, utvrditi njegovo današnje dendrološko bogatstvo i usporediti ga sa stanjem iz 1962. i 1995. godine.

\section{MATERIJAL I METODE MATERIALS AND METHODS}

Radi utvrđivanja sadašnjega stanja dendroflore u Parku kralja Petra Krešimira IV. u Zagrebu, biljke su determinirane u razdoblju od ljeta 2018. do ljeta 2019. godine, jer je za točno određivanje pojedinih svojti bilo potrebno obuhvatiti i vegetativnu i generativnu fazu. Za potvrdu determinacije pojedinih svojti korištena je sljedeća literatura: Brickell (2003), Hillier i Lancaster (2014), Idžojtić (2005, 2009, 2013, 2019), Kelly (2004), Krüssmann $(1972,1976)$ i Roloff i sur. (1994-2019). Prema prikupljenim podacima napravljena je dendrološka analiza drvenastih biljaka u parku, a analizirani su sljedeći podaci: brojnost pojedinih svojti (vrsta, podvrsta, varijeteta, križanaca i kultivara), pripadnost porodici, areal, habitus, trajnost listova, cvjetovi, vrijeme cvjetanja, plodovi, broj autohtonih svojti i broj alohtonih svojti s pojedinih kontinenata. Iz literature su korišteni popisi drvenastih svojti prisutnih u parku prije 57 godina (Karavla 1962) i prije 24 godine (Turk 1995). 
Znanstveni nazivi svojti navedeni su prema Erhardtu i sur. (2014) i bazi podataka International Plant Names Index (IPNI), sukladno djelu International Code of Nomenclature for algae, fungi and plants (Turland i sur. 2018). Imena autora znanstvenih naziva standardizirana su prema djelu Brummitt i Powell (1992). Hrvatski nazivi vrsta navedeni su prema Aniću (1946), Hermanu (1971), Idžojtić (2005, 2009, 2013), Vidakoviću $(1982,1993)$ i prema Šumarskoj enciklopediji I-III $(1980,1983,1987)$. Nazivi kultivara navedeni su prema Hoffman (2016), sukladno djelu International Code of Nomenclature for Cultivated Plants (Brickell i sur. 2016). Pripadnost porodicama navedena je prema Cronquistu (1981), Dahlgrenu i sur. (1985), Krameru i Greenu (1990) i Farjonu (2010).

\section{REZULTATI I RASPRAVA}

\section{RESULTS AND DISCUSSION}

Tijekom 2018. i 2019. godine, u Parku kralja Petra Krešimira IV., na istoimenom trgu u Zagrebu, determinirane su 122 drvenaste svojte (tablica 1). Od toga sedam svojti pripada golosjemenjačama, a ostalo su kritosjemenjače. Zabilježene su 83 vrste (šest golosjemenjača i 77 kritosjemenjača), dvije podvrste (obje kritosjemenjače), 30 kultivara (jedna golosjemenjača i 29 kritosjemenjača), šest križanaca (svi kritosjemenjače) i jedan varijetet (kritosjemenjača). Determinirane svojte pripadaju u 36 različitih porodica i 67 rodova, od čega golosjemenjačama pripadaju četiri porodice i sedam rodova. Svojtama najbrojniji rodovi su: Acer L. - javori (9), Prunus L. (6), Berberis L. - žutike i Lonicera L. - kozokrvine (po 5) te Cornus L. - drijenovi i Spiraea L. - suručice (po 4).

Prvi popis drvenastih svojti u parku na tadašnjem Lenjinovom, danas Trgu kralja Petra Krešimira IV. napravio je Karavla (1962). On tada bilježi 78 svojti drveća i grmlja (tablica 1) od kojih neke nisu zabilježene niti na jednom kasnijem popisu: grozdasta žutika (Berberis aggregata), ljetni jorgovan (Buddleja davidii), patisa (Cephalotaxus haringtonii), žuto drvo (Cladrastis lutea), mušmulice (Cotoneaster dielsianus i C. nitidus), crveni glog (Crataegus mollis), Fortuneova kurika (Euonymus fortunei), kultivar 'Variegatus' Fortuneove kurike (E. fortunei 'Variegatus'), rani jasmin (Jasminum nudiflorum), kultivar 'Plumosa' kineske borovice (Juniperus chinensis 'Plumosa'), kultivar 'Aureoreticulata' japanske kozokrvine (Lonicera japonica 'Aureoreticulata'), kultivar 'Elise Rathke' ukrasne jabuke (Malus 'Elise Rathke'), kultivar 'Friedrichsenii' grmastog petoprsnika (Potentilla fruticosa 'Friedrichsenii'), pteleja (Ptelea trifoliata), kultivar 'Inermis' običnog bagrema (Robinia pseudoacacia 'Inermis'), mandžurska ruža (Rosa xanthiana 'Hugonis'), velecvjetna ruža (R. multiflora), kineska žalosna vrba (Salix babylonica), suručica (Spiraea $\times$ bumalda), snježna lopta (Viburnum opulus 'Roseum') te kineska glicinija (Wisteria sinensis).

Od drveća sađenog u vrijeme osnivanja parka svojim izgledom i dimenzijama ističu se: ginko (Ginkgo biloba), hibridne platane (Platanus $\times$ hispanica), virdžinijski dragun (Diospyros virginiana) i mandžurski plutnjak (Phellodendron amurense). Od cvjetnih ukrasnih grmova značajni su: kultivar 'Atropurpurea' Thunbergove žutike (Berberis $\times$ thunbergii 'Atropurpurea'), japanska dunjica (Chaenomeles japonica), cvijetni drijen (Cornus florida), japanska malolisna kalina (Ligustrum ovalifolium), ranocvjetna kozokrvina (Lonicera $\times$ purpusii), lovorvišnja (Prunus laurocerasus), ružičasta vajgelija (Weigela florida) i druge. To su svojte koje se zajedno s još 18 svojti nalaze na svim popisima dendroflore ovoga parka. Devet svojti zabilježeno je 1962. i 2019. godine, ali ne i 1995., što potencijalno može biti rezultat nepotpune ili krive determinacije, uzmemo li u obzir da Jurković i Jurković (1997) opisuju stablo američkoga koprivića (Celtis occidentalis) visine 14,5 m te prsnog promjera $72 \mathrm{~cm}$, a ono se ne nalazi na popisu iz 1995. godine. Slična je situacija sa stablom dudovca (Broussonetia papyrifera), koje je evidentno starije od 24 godine, iako se ne nalazi na popisu iz 1995. godine.

Sljedeći popis drvenastih biljaka unutar parka daje Turk (1995), prema kojemu su u to vrijeme u parku bile prisutne 93 svojte drveća i grmlja (tablica 1). U razdoblju od 1995. godine do danas u park je introducirano 65 svojti koje prije toga u njemu nisu bile prisutne, kao npr. obična breza (Betula pendula), obično Judino drvo (Cercis siliquastrum), vitka i hrapava dojcija (Deutzia gracilis i D. scabra), hrastolisna hortenzija (Hydrangea quercifolia), sjajna i kalinasta kozokrvina (Lonicera nitida i L. pileata), pahisandra (Pachysandra terminalis), paulovnija (Paulownia tomentosa), vatreni trn (Pyracantha coccinea) i druge. S druge strane, neke vrste poput plave kupine (Rubus caesius), sviba (Cornus sanguinea), crne bazge (Sambucus nigra), bijeloga duda (Morus alba), nizinskoga brijesta (Ulmus minor) i pajasena ( $A i-$ lanthus altissima) samoniklo su se pojavile u parku i dio njih je potrebno ukloniti kako ne bi ometale rast i razvoj ostalog bilja, što se prvenstveno odnosi na plavu kupinu i pajasen. Dio navedenog samoniklog bilja mogao bi se uklopiti u strukturu parka, kao na primjer crna bazga i svib, čijim se plodovima hrane ptice i koje svojim ukrasnim bijelim cvjetovima doprinose proljetnom šarenilu parka. Od u novije vrijeme posađenih kultivara ističu se: kultivar bijelo obrubljenih listova 'Elegantissima' sibirskoga drijena i kultivar svijetložuto obrubljenih listova 'Lemon Beauty' sjajne kozokrvine, kultivari crvenih listova Acer palmatum 'Atropurpureum' i Corylus maxima 'Purpurea', kultivari Fortuneove kurike različito obojenoga lišća ('Emerald Gaiety', 'Emerald ' $n$ ' Gold,' 'Sunspot'), kultivar polegnutoga habitusa 'Parkteppich' vrbolisne mušmulice, kultivari stupastoga habitusa Populus simonii 'Fastigiata' i P. nigra 'Italica', kultivar 
Tablica 1. Popis drvenastih svojti u Parku kralja Petra Krešimira IV.: prije 57 godina (Karavla 1962), prije 24 godine (Turk 1995) i sadašnje stanje (2019. godine).

Kratice i simboli: Areal: Afr $=$ Afrika, Az = Azija, Eu = Europa, Medit = Mediteran, Sj Am = Sjeverna Amerika; $\times=$ križanac, $c v=$ kultivar. Prisutnost svojte: $\bullet=$ svojta prisutna, $-=$ svojta nije prisutna, ${ }^{*}=1962$. ili 1995 . godine svojta zabilježena pod nazivom: * 1 Acer mono Maxim., *2 Cephalotaxus drupacea pedunculata Miq., *3 Clematis montana rubens Ktze., *4 Corylus avellana 'Atropurpurea', *5 Cotinus coggygria 'Red Chif' (nepoznati kultivar), *6 Cotoneaster disticha Lange, * 7 Evonymus Fortunei radicans (Miq.) Rehd., *8 Euonymus Fortunei gracilis (Reg.) Rehd., *9 Malus pumila pendula (Zab.) Schneid („Elise Rathke“), *10 Philadelphus floribundus Schrad. (nije jasno na koju se vrstu odnosi), *11 Rosa hugonis Hemsl., *12 Chamaecyparis lawsoniana 'Filiformis'.

Table 1 List of woody taxa in the Park Kralj Petar Krešimir IV: 57 years ago (Karavla 1962), 24 years ago (Turk 1995), and the present state (2019). Abbreviations and Symbols: Distribution: Afr = Africa, Az = Asia, Eu = Europe, Medit = Mediterranean, Sj Am = North America; $\times=$ hybrid, $c v=$ cultivar.

The presence of taxa: $\bullet=$ taxon present, $-=$ taxon not present, ${ }^{*}=$ in 1962 or 1995 taxon recorded under the name: * 1 Acer mono Maxim., ${ }^{*} 2$ Cephalotaxus drupacea pedunculata Miq., *3 Clematis montana rubens Ktze., "*4 Corylus avellana 'Atropurpurea', *5 Cotinus coggygria 'Red Chif' (unknown cultivar), *6 Cotoneaster disticha Lange, *7 Evonymus Fortunei radicans (Miq.) Rehd., *8 Euonymus Fortunei gracilis (Reg.) Rehd., ${ }^{*} 9$ Malus pumila pendula (Zab.) Schneid („Elise Rathke“), *10 Philadelphus floribundus Schrad. (it is not clear which species it is referring to), ${ }^{*} 11$ Rosa hugonis Hemsl., ${ }^{*} 12$ Chamaecyparis lawsoniana 'Filiformis'.

\begin{tabular}{|c|c|c|c|c|c|}
\hline $\begin{array}{l}\text { Svojta } \\
\text { Taxon }\end{array}$ & $\begin{array}{l}\text { Areal } \\
\text { Distribution }\end{array}$ & $\begin{array}{l}\text { Porodica } \\
\text { Family }\end{array}$ & 1962. & 1995. & 2019. \\
\hline Acer campestre L. & Eu, Afr, Az & Aceraceae & - & - *1 & $\bullet$ \\
\hline Acer japonicum Thunb. & $\mathrm{Az}$ & Aceraceae & - & $\bullet$ & - \\
\hline Acer negundo L. & Sj Am & Aceraceae & $\bullet$ & $\bullet$ & $\bullet$ \\
\hline Acer palmatum Thunb. ex E. Murray & $\mathrm{Az}$ & Aceraceae & - & $\bullet$ & $\bullet$ \\
\hline Acer palmatum 'Atropurpureum' & cv & Aceraceae & - & - & $\bullet$ \\
\hline Acer platanoides $\mathrm{L}$. & $\mathrm{Eu}, \mathrm{Az}$ & Aceraceae & - & $\bullet$ & $\bullet$ \\
\hline Acer pseudoplatanus L. & $\mathrm{Eu}, \mathrm{Az}$ & Aceraceae & - & $\bullet$ & $\bullet$ \\
\hline Acer pseudoplatanus 'Atropurpureum' & $\mathrm{cv}$ & Aceraceae & - & - & $\bullet$ \\
\hline Acer saccharinum $\mathrm{L}$. & Sj Am & Aceraceae & $\bullet$ & $\bullet$ & $\bullet$ \\
\hline Acer saccharinum 'Laciniatum Wieri' & cv & Aceraceae & - & - & $\bullet$ \\
\hline Acer tataricum subsp. ginnala (Maxim.) Wesm. & $\mathrm{Az}$ & Aceraceae & - & $\bullet$ & - \\
\hline Aesculus hippocastanum L. & $\mathrm{Eu}$ & Hippocastanaceae & - & $\bullet$ & $\bullet$ \\
\hline Ailanthus altissima (Mill.) Swingle & $\mathrm{Az}$ & Simaroubaceae & $\bullet$ & - & $\bullet$ \\
\hline Alnus glutinosa (L.) Gaertn. & $\mathrm{Eu}, \mathrm{Az}, \mathrm{Afr}$ & Betulaceae & - & $\bullet$ & $\bullet$ \\
\hline Berberis aggregata C.K. Schneid. & $\mathrm{Az}$ & Berberidacae & $\bullet$ & - & - \\
\hline Berberis gagnepainii var. lanceifolia Ahrendt & $\mathrm{Az}$ & Berberidaceae & $\bullet$ & - & $\bullet$ \\
\hline Berberis julianae C.K. Schneid. & $\mathrm{Az}$ & Berberidaceae & - & $\bullet$ & $\bullet$ \\
\hline Berberis $\times$ ottawensis C.K. Schneider & $\times$ & Berberidaceae & - & - & $\bullet$ \\
\hline Berberis $\times$ stenophylla Lindl. & $\times$ & Berberidaceae & - & $\bullet$ & - \\
\hline Berberis thunbergii DC. & $\mathrm{Az}$ & Berberidaceae & - & - & $\bullet$ \\
\hline Berberis thunbergii 'Atropurpurea' & cV & Berberidaceae & $\bullet$ & $\bullet$ & $\bullet$ \\
\hline Berberis verruculosa Hemsl. et E.H. Wilson & $\mathrm{Az}$ & Berberidaceae & $\bullet$ & $\bullet$ & - \\
\hline Betula pendula Roth & $\mathrm{Eu}, \mathrm{Az}$ & Betulaceae & - & - & $\bullet$ \\
\hline Betula pendula 'Youngii' & cv & Betulaceae & - & $\bullet$ & - \\
\hline Broussonetia papyrifera (L.) Vent. & $A z$ & Moraceae & $\bullet$ & - & $\bullet$ \\
\hline Buddleja davidii Franch. & $\mathrm{Az}$ & Oleaceae & $\bullet$ & - & - \\
\hline Buxus sempervirens L. & $\mathrm{Eu}, \mathrm{Afr}, \mathrm{Az}$ & Buxaceae & - & - & $\bullet$ \\
\hline Calycanthus floridus $\mathrm{L}$. & Sj Am & Calycanthaceae & - & $\bullet$ & $\bullet$ \\
\hline Campsis radicans (L.) Seem. ex Bureau & Sj Am & Bignoniaceae & - & $\bullet$ & - \\
\hline Carpinus betulus $\mathrm{L}$. & $\mathrm{Eu}, \mathrm{Az}$ & Betulaceae & - & $\bullet$ & $\bullet$ \\
\hline Catalpa bignonioides Walter & Sj Am & Bignoniaceae & $\bullet$ & $\bullet$ & $\bullet$ \\
\hline Catalpa speciosa (Warder ex Barney) Engelm. & $\mathrm{Sj} \mathrm{Am}$ & Bignoniaceae & - & - & $\bullet$ \\
\hline Celtis australis L. & $\mathrm{Eu}, \mathrm{Afr}, \mathrm{Az}$ & Ulmaceae & - & - & $\bullet$ \\
\hline Celtis occidentalis L. & $\mathrm{Sj} \mathrm{Am}$ & Ulmaceae & - & - & $\bullet$ \\
\hline Cephalotaxus haringtonii (Knightex J. Forbes) K. Koch & $A z$ & Cephalotaxaceae & $\bullet * 2$ & - & - \\
\hline Cercis siliquastrum L. & Medit & Fabaceae & - & - & $\bullet$ \\
\hline Chaenomeles japonica (Thunb.) Lindl. ex. Spach & $\mathrm{Az}$ & Rosaceae & $\bullet$ & $\bullet$ & $\bullet$ \\
\hline Chamaecyparis lawsoniana (A. Murray bis) Parl. & Sj Am & Cupressaceae & $\bullet$ & $\bullet$ & $\bullet$ \\
\hline Cladrastis lutea (Michx.) K. Koch. & Sj Am & Fabaceae & $\bullet$ & - & - \\
\hline Clematis montana var. rubens $\mathrm{E} . \mathrm{H}$. Wilson & $\mathrm{Az}$ & Ranunculaceae & $\bullet * 3$ & - & - \\
\hline Cornus alba L. & $\mathrm{Az}$ & Cornaceae & $\bullet$ & $\bullet$ & $\bullet$ \\
\hline Cornus alba 'Elegantissima' & $\mathrm{cV}$ & Cornaceae & - & - & $\bullet$ \\
\hline Cornus florida L. & Sj Am & Cornaceae & $\bullet$ & $\bullet$ & $\bullet$ \\
\hline Cornus sanguinea L. & $\mathrm{Eu}$ & Cornaceae & - & - & $\bullet$ \\
\hline Corylus avellana L. & $\mathrm{Eu}, \mathrm{Az}$ & Betulaceae & - & - & - \\
\hline Corylus colurna L. & $\mathrm{Eu}, \mathrm{Az}$ & Betulaceae & - & - & $\bullet$ \\
\hline Corylus maxima 'Purpurea' & $\mathrm{Eu}, \mathrm{Az}$ & Betulaceae & - & - 4 & $\bullet$ \\
\hline Cotinus coggygria Scop. & $\mathrm{Eu}, \mathrm{Az}$ & Anacardiaceae & - & $\bullet$ & - \\
\hline Cotinus coggygria 'Red Chif' & $\mathrm{cv}$ & Anacardiaceae & - & $\bullet * 5$ & - \\
\hline Cotoneaster dammeri C.K. Schneid. & $A z$ & Rosaceae & $\bullet$ & $\bullet$ & - \\
\hline
\end{tabular}




\begin{tabular}{|c|c|c|c|c|c|}
\hline $\begin{array}{l}\text { Svojta } \\
\text { Taxon }\end{array}$ & $\begin{array}{l}\text { Areal } \\
\text { Distribution }\end{array}$ & $\begin{array}{l}\text { Porodica } \\
\text { Family }\end{array}$ & 1962. & 1995. & 2019 \\
\hline Cotoneaster dielsianus E. Pritz. & $\mathrm{Az}$ & Rosaceae & $\bullet$ & - & - \\
\hline Cotoneaster horizontalis Decne. & $A z$ & Rosaceae & $\bullet$ & $\bullet$ & $\bullet$ \\
\hline Cotoneaster nitidus Jacques var. nitidus & $\mathrm{Az}$ & Rosaceae & -*6 & - & - \\
\hline Cotoneaster salicifolius 'Parkteppich' & cv & Rosaceae & - & - & $\bullet$ \\
\hline Crataegus $\times$ lavalleei 'Carrierei' & cv & Rosaceae & - & - & $\bullet$ \\
\hline Crataegus collina Champ. & Sj Am & Rosaceae & - & $\bullet$ & - \\
\hline Crataegus mollis (Torr. et A. Gray) Scheele & Sj Am & Rosaceae & $\bullet$ & - & - \\
\hline Deutzia gracilis Siebold et Zucc. & $\mathrm{Az}$ & Hydrangeaceae & & - & $\bullet$ \\
\hline Deutzia scabra Thunb. & $\mathrm{Az}$ & Hydrangeaceae & - & - & $\bullet$ \\
\hline Diospyros virginiana $\mathrm{L}$. & Sj Am & Ebenaceae & $\bullet$ & $\bullet$ & $\bullet$ \\
\hline Euonymus fortunei (Turcz.) Hand.-Mazz. & $\mathrm{Az}$ & Celastraceae & -*7 & - & - \\
\hline Euonymus fortunei 'Emerald Gaiety' & cv & Celastraceae & - & - & $\bullet$ \\
\hline Euonymus fortunei 'Emerald 'n' Gold' & cv & Celastraceae & - & - & $\bullet$ \\
\hline Euonymus fortunei 'Variegatus' & cv & Celastraceae & -*8 & - & - \\
\hline Euonymus fortunei 'Sunspot' & cv & Celastraceae & - & - & $\bullet$ \\
\hline Fagus sylvatica L. & $\mathrm{Eu}$ & Fagaceae & - & - & $\bullet$ \\
\hline Fagus sylvatica 'Atropunicea' & cv & Fagaceae & $\bullet$ & - & - \\
\hline $\begin{array}{l}\text { Fontanesia phillyreoides subsp. fortunei (Cariérre) P.S. } \\
\text { Green et Yalt. }\end{array}$ & $\mathrm{Az}$ & Oleaceae & - & $\bullet$ & $\bullet$ \\
\hline Forsythia $\times$ intermedia Zabel & $\times$ & Oleaceae & - & - & $\bullet$ \\
\hline Forsythia suspensa (Thunb.) Vahl & $\mathrm{Az}$ & Oleaceae & $\bullet$ & $\bullet$ & $\bullet$ \\
\hline Fraxinus angustifolia Vahl & $\mathrm{Eu}, \mathrm{Az}, \mathrm{Afr}$ & Oleaceae & - & - & $\bullet$ \\
\hline Fraxinus pennsylvanica Marshall & $\mathrm{Sj} \mathrm{Am}$ & Oleaceae & - & - & $\bullet$ \\
\hline Ginkgo biloba L. & $\mathrm{Az}$ & Ginkgoaceae & $\bullet$ & $\bullet$ & $\bullet$ \\
\hline Gymnocladus dioicus (L.) K. Koch & Sj Am & Caesalpiniaceae & $\bullet$ & $\bullet$ & $\bullet$ \\
\hline Hedera helix L. & $\mathrm{Eu}, \mathrm{Aft}, \mathrm{Az}$ & Araliaceae & - & - & $\bullet$ \\
\hline Hedera helix ‘Goldchild' & $\mathrm{cV}$ & Araliaceae & - & - & $\bullet$ \\
\hline Hedera helix 'Green Ripple' & cv & Araliaceae & - & - & $\bullet$ \\
\hline Hibiscus syriacus $\mathrm{L}$. & $A z$ & Malvaceae & - & - & $\bullet$ \\
\hline Hibiscus syriacus 'Red Heart' & $\mathrm{cv}$ & Malvaceae & - & - & $\bullet$ \\
\hline Hydrangea arborescens $\mathrm{L}$. & Sj Am & Hydrangeaceae & - & $\bullet$ & - \\
\hline Hydrangea arborescens 'Grandiflora' & cv & Hydrangeaceae & - & - & $\bullet$ \\
\hline Hydrangea macrophylla (Thunb. ex Murray) Ser. & $\mathrm{Az}$ & Hydrangeaceae & - & - & $\bullet$ \\
\hline Hydrangea quercifolia W. Bartram & Sj Am & Hydrangeaceae & - & - & $\bullet$ \\
\hline Hypericum calycinum L. & Sj Am, Az & Clusiaceae & - & $\bullet$ & - \\
\hline Ilex aquifolium $\mathrm{L}$. & $\mathrm{Eu}, \mathrm{Az}, \mathrm{Afr}$ & Aquifoliaceae & - & $\bullet$ & $\bullet$ \\
\hline Ilex $\times$ meserveae 'Blue Angel' & $\mathrm{cv}$ & Aquifoliaceae & - & - & $\bullet$ \\
\hline Jasminum nudiflorum Lindl. & $A z$ & Oleaceae & $\bullet$ & - & - \\
\hline Juniperus chinensis L. & $A z$ & Cupressaceae & - & $\bullet$ & - \\
\hline Juniperus chinensis 'Plumosa' & cv & Cupressaceae & $\bullet$ & - & - \\
\hline Juniperus communis 'Hibernica' & $\mathrm{cv}$ & Cupressaceae & $\bullet$ & $\bullet$ & - \\
\hline Juniperus sabina L. & $\mathrm{Eu}, \mathrm{Az}$ & Cupressaceae & $\bullet$ & $\bullet$ & - \\
\hline Juniperus virginiana L. & Sj Am & Cupressaceae & $\bullet$ & $\bullet$ & - \\
\hline Ligustrum obtusifolium Siebold et Zucc. & $\mathrm{Az}$ & Oleaceae & - & - & $\bullet$ \\
\hline Ligustrum ovalifolium Hassk. & $\mathrm{Az}$ & Oleaceae & $\bullet$ & $\bullet$ & $\bullet$ \\
\hline Liquidambar orientalis Mill. & $\mathrm{Az}$ & Hamamelidaceae & - & - & $\bullet$ \\
\hline Liquidambar styraciflua L. & Sj Am & Hamamelidaceae & $\bullet$ & $\bullet$ & $\bullet$ \\
\hline Liriodendron tulipifera L. & Sj Am & Magnoliaceae & $\bullet$ & $\bullet$ & $\bullet$ \\
\hline Lonicera $\times$ brownii 'Fuchsioides' & $\mathrm{cv}$ & Caprifoliaceae & $\bullet$ & $\bullet$ & - \\
\hline Lonicera japonica 'Aureoreticulata' & $\mathrm{cv}$ & Caprifoliaceae & $\bullet$ & - & - \\
\hline Lonicera nitida E.H. Wilson & $A z$ & Caprifoliaceae & - & - & $\bullet$ \\
\hline Lonicera nitida 'Lemon Beauty' & cv & Caprifoliaceae & - & - & $\bullet$ \\
\hline Lonicera pileata Oliv. & $A z$ & Caprifoliaceae & $\bullet$ & - & $\bullet$ \\
\hline Lonicera $\times$ purpusii Rehder & $\times$ & Caprifoliaceae & $\bullet$ & $\bullet$ & $\bullet$ \\
\hline Lonicera tatarica $\mathrm{L}$. & $\mathrm{Az}$ & Caprifoliaceae & - & $\bullet$ & $\bullet$ \\
\hline Mahonia aquifolium (Pursh) Nutt. & Sj Am & Berberidaceae & - & $\bullet$ & $\bullet$ \\
\hline Malus 'Elise Rathke' & cv & Rosaceae & $\bullet * 9$ & - & - \\
\hline Malus floribunda Siebold ex Van Houtte & $\mathrm{Az}$ & Rosaceae & - & $\bullet$ & - \\
\hline Morus alba L. & $\mathrm{Az}$ & Moraceae & - & - & $\bullet$ \\
\hline Morus alba 'Pendula' & $\mathrm{cv}$ & Moraceae & $\bullet$ & - & - \\
\hline Pachysandra terminalis Siebold et Zucc. & $A z$ & Buxaceae & - & - & $\bullet$ \\
\hline Paeonia $\times$ suffruticosa Andrews & $x$ & Paeoniaceae & - & - & - \\
\hline Parrotia persica (DC.) C.A. Mey. & $\mathrm{Az}$ & Hamamelidaceae & - & - & $\bullet$ \\
\hline Parthenocissus quinquefolia (L.) Planch. & Sj Am & Vitaceae & - & - & $\bullet$ \\
\hline Parthenocissus tricuspidata (Siebold. et Zucc.) Planch. & $\mathrm{Az}$ & Vitaceae & - & $\bullet$ & $\bullet$ \\
\hline Paulownia tomentosa (Thunb. ex Murray) Steud. & $\mathrm{Az}$ & Scrophulariaceae & - & - & - \\
\hline Phellodendron amurense Rupr. & $\mathrm{Az}$ & Rutaceae & - & - & - \\
\hline Philadelphus coronarius L. & $\mathrm{Eu}, \mathrm{Az}$ & Hydrangeaceae & - & - & - \\
\hline
\end{tabular}




\begin{tabular}{|c|c|c|c|c|c|}
\hline $\begin{array}{l}\text { Svojta } \\
\text { Taxon }\end{array}$ & $\begin{array}{l}\text { Areal } \\
\text { Distribution }\end{array}$ & $\begin{array}{l}\text { Porodica } \\
\text { Family }\end{array}$ & 1962. & 1995. & 2019 \\
\hline Philadelphus spp. & & Hydrangeaceae & $\bullet * 10$ & - & - \\
\hline Picea pungens Engelm. & Sj Am & Pinaceae & - & $\bullet$ & $\bullet$ \\
\hline Pinus nigra J.F. Arnold & $\mathrm{Eu}, \mathrm{Afr}, \mathrm{Az}$ & Pinaceae & - & - & $\bullet$ \\
\hline Pinus peuce Griseb. & $\mathrm{Eu}$ & Pinaceae & - & $\bullet$ & - \\
\hline Pinus sylvestris L. & $\mathrm{Eu}, \mathrm{Az}$ & Pinaceae & - & $\bullet$ & - \\
\hline Platanus × hispanica Münchh. & $\times$ & Platanaceae & $\bullet$ & $\bullet$ & $\bullet$ \\
\hline Platycladus orientalis (L.) Franco & $\mathrm{Az}$ & Cupressaceae & $\bullet$ & $\bullet$ & - \\
\hline Populus $\times$ berolinensis (K. Koch) Dippel & $\times$ & Salicaceae & $\bullet$ & $\bullet$ & - \\
\hline Populus nigra 'Italica' & cv & Salicaceae & $\bullet$ & - & $\bullet$ \\
\hline Populus simonii 'Fastigiata' & cv & Salicaceae & - & - & $\bullet$ \\
\hline Potentilla fruticosa 'Friedrichsenii' & $\mathrm{cv}$ & Rosaceae & $\bullet$ & - & - \\
\hline Prunus avium (L.) L. & $\mathrm{Eu}, \mathrm{Az}, \mathrm{Afr}$ & Rosaceae & - & - & $\bullet$ \\
\hline Prunus cerasifera Ehrh. & $\mathrm{Az}$ & Rosaceae & - & - & $\bullet$ \\
\hline Prunus cerasifera 'Nigra' & cv & Rosaceae & - & - & $\bullet$ \\
\hline Prunus cerasifera 'Pissardii' & $\mathrm{cv}$ & Rosaceae & $\bullet$ & $\bullet$ & $\bullet$ \\
\hline Prunus laurocerasus L. & $\mathrm{Eu}, \mathrm{Az}$ & Rosaceae & $\bullet$ & $\bullet$ & $\bullet$ \\
\hline Prunus laurocerasus 'Otto Luyken' & $\mathrm{cv}$ & Rosaceae & - & $\bullet$ & - \\
\hline Prunus laurocerasus 'Schipkaensis' & $\mathrm{cv}$ & Rosaceae & - & - & $\bullet$ \\
\hline Prunus mahaleb L. & $\mathrm{Eu}, \mathrm{Az}, \mathrm{Afr}$ & Rosaceae & - & $\bullet$ & - \\
\hline Prunus serotina Ehrh. & Sj Am & Rosaceae & $\bullet$ & $\bullet$ & - \\
\hline Prunus serrulata 'Hissakura' & $\mathrm{cv}$ & Rosaceae & $\bullet$ & $\bullet$ & - \\
\hline Prunus serrulata 'Kanzan' & cv & Rosaceae & - & $\bullet$ & - \\
\hline Prunus 'Kiku-shidare-zakura' & $\mathrm{cv}$ & Rosaceae & $\bullet$ & $\bullet$ & - \\
\hline Pseudotsuga menziesii (Mirb.) Franco var. menziesii & Sj Am & Pinaceae & - & $\bullet$ & - \\
\hline Ptelea trifoliata L. & Sj Am & Rutaceae & $\bullet$ & - & - \\
\hline Pyracantha coccinea M. Roem. & Medit & Rosaceae & - & - & $\bullet$ \\
\hline Quercus robur $\mathrm{L}$. & $\mathrm{Eu}, \mathrm{Afr}, \mathrm{Az}$ & Fagaceae & - & $\bullet$ & $\bullet$ \\
\hline Quercus robur 'Fastigiata' & $\mathrm{cv}$ & Fagaceae & - & $\bullet$ & $\bullet$ \\
\hline Quercus rubra L. & Sj Am & Fagaceae & - & $\bullet$ & $\bullet$ \\
\hline Rhododendron maximum L. & $\mathrm{cv}$ & Ericaceae & - & $\bullet$ & - \\
\hline Robinia pseudoacacia 'Inermis' & cv & Fabaceae & $\bullet$ & - & - \\
\hline Robinia pseudoacacia 'Umbraculifera' & cv & Fabaceae & $\bullet$ & $\bullet$ & $\bullet$ \\
\hline Rosa xanthiana 'Hugonis' & $\mathrm{cv}$ & Rosaceae & $\bullet * 11$ & - & - \\
\hline Rosa multiflora Thunb. & $\mathrm{Az}$ & Rosaceae & $\bullet$ & - & - \\
\hline Rubus caesius L. & $\mathrm{Eu}, \mathrm{Az}$ & Rosaceae & - & - & $\bullet$ \\
\hline Salix babylonica L. & $\mathrm{Az}$ & Salicaceae & $\bullet$ & - & - \\
\hline Salix caprea L. & $\mathrm{Eu}, \mathrm{Az}$ & Salicaceae & - & $\bullet$ & - \\
\hline Salix $\times$ sepulcralis 'Chrysocoma' & $\mathrm{cv}$ & Salicaceae & - & $\bullet$ & $\bullet$ \\
\hline Sambucus nigra L. & $\mathrm{Eu}, \mathrm{Az}, \mathrm{Afr}$ & Caprifoliaceae & - & - & $\bullet$ \\
\hline Spiraea $\times$ bumalda Burv. & $\times$ & Rosaceae & $\bullet$ & - & - \\
\hline Spiraea japonica L. f. & $\mathrm{Az}$ & Rosaceae & - & $\bullet$ & $\bullet$ \\
\hline Spiraea japonica 'Albiflora' & cv & Rosaceae & - & - & $\bullet$ \\
\hline Spiraea japonica 'Anthony Waterer' & cv & Rosaceae & - & - & $\bullet$ \\
\hline Spiraea $\times$ vanhouttei (Briot) Zabel & $\times$ & Rosaceae & $\bullet$ & - & $\bullet$ \\
\hline Styphnolobium japonicum (L.) Schott & $\mathrm{Az}$ & Fabaceae & $\bullet$ & $\bullet$ & - \\
\hline Styphnolobium japonicum 'Pendula' & $\mathrm{cv}$ & Fabaceae & $\bullet$ & $\bullet$ & $\bullet$ \\
\hline Symphoricarpos albus (L.) S.F. Blake & Sj Am & Caprifoliaceae & $\bullet$ & $\bullet$ & $\bullet$ \\
\hline Symphoricarpos orbiculatus Moench & Sj Am & Caprifoliaceae & $\bullet$ & $\bullet$ & $\bullet$ \\
\hline Taxus baccata L. & Eu, Afr, Az & Taxaceae & - & $\bullet$ & $\bullet$ \\
\hline Thuja occidentalis L. & Sj Am & Cupressaceae & $\bullet$ & $\bullet$ & $\bullet$ \\
\hline Thuja plicata 'Sempervirens' & cv & Cupressaceae & - & $\bullet$ & - \\
\hline Tilia cordata Mill. & $\mathrm{Eu}$ & Tiliaceae & - & $\bullet$ & $\bullet$ \\
\hline Tilia platyphyllos Scop. & $\mathrm{Eu}$ & Tiliaceae & - & - & $\bullet$ \\
\hline Tilia tomentosa Moench & $\mathrm{Eu}, \mathrm{Az}$ & Tiliaceae & - & - & $\bullet$ \\
\hline Ulmus minor Mill. & $\mathrm{Eu}, \mathrm{Az}, \mathrm{Afr}$ & Ulamaceae & - & - & $\bullet$ \\
\hline Viburnum opulus $\mathrm{L}$. & $\mathrm{Eu}, \mathrm{Afr}$ & Caprifoliaceae & - & $\bullet$ & - \\
\hline Viburnum opulus 'Roseum' & $\mathrm{cv}$ & Caprifoliaceae & $\bullet$ & - & - \\
\hline Viburnum $\times$ pragense Vikulova & $x$ & Caprifoliaceae & & - & $\bullet$ \\
\hline Viburnum rhytidophyllum Hemsl. & $\mathrm{Az}$ & Caprifoliaceae & $\bullet$ & $\bullet$ & $\bullet$ \\
\hline Vinca major $\mathrm{L}$. & $\mathrm{Eu}, \mathrm{Az}$ & Apocynaceae & - & $\bullet$ & $\bullet$ \\
\hline Vinca major 'Maculata' & $\mathrm{cv}$ & Apocynaceae & - & - & $\bullet$ \\
\hline Vinca minor L. & $\mathrm{Eu}, \mathrm{Az}$ & Apocynaceae & - & - & $\bullet$ \\
\hline Vitis spp. & & Vitaceae & $\bullet$ & - & - \\
\hline Vitis vinifera subsp. sylvestris (C.C. Gmel.) Hegi & $\mathrm{Eu}, \mathrm{Az}, \mathrm{Afr}$ & Vitaceae & - & $\bullet$ & $\bullet$ \\
\hline Weigela florida (Bunge) A. DC. & $\mathrm{Az}$ & Caprifoliaceae & $\bullet$ & $\bullet$ & $\bullet$ \\
\hline Wisteria sinensis (Sims.) Sweet. & $A z$ & Fabaceae & $\bullet$ & - & - \\
\hline Xanthocyparis nootkatensis 'Pendula' & cv & Cupressaceae & - & $\bullet * 12$ & $\bullet$ \\
\hline
\end{tabular}


sterilnih, zelenkastobijelih cvjetova u kuglasto spljoštenim cvatovima 'Grandiflora' drvolike hortenzije i drugi.

Prema trajnosti listova u parku dominiraju listopadne svojte, kojih je 88 (jedna golosjemenjača i 87 kritosjemenjača), zatim vazdazelene (šest golosjemenjača i 24 kritosjemenjače), a prisutna je i jedna zimzelena vrsta (Ligustrum ovalifolium). Osim toga, dvije kritosjemenjače se opisuju kao listopadne do zimzelene (Cotoneaster horizontalis i Lonicera $\times$ purpusii), dok jednu karakterizira vazdazeleno do zimzeleno lišće (Pyracantha coccinea).

Što se tiče habitusa, stabla i grmovi su podjednako zastupljeni. Kao stablo raste 56 svojti (sedam golosjemenjača i 49 kritosjemenjača), dok je grmova samo jedna svojta manje i sve su kritosjemenjače. Četiri kritosjemenjače su polugrmovi, pet je penjačica, a dvije vrste mogu rasti kao stabla i kao grmovi (Parrotia persica i Taxus baccata).

Svojte s ukrasnim cvjetovima vrlo su važan element svakog gradskog parka, jer mu daju živopisnost, dinamiku i boju tijekom cijele godine. Krajem zime u parku mirisom i bojom pozornost privlače grmovi ranocvjetne kozokrvine (Lonicera $\times$ purpusii). Nešto kasnije, u ožujku i travnju, svojim žutim cvjetovima park krase forzicije (Forsythia $\times$ intermedia i F. suspensa, slika 1) i mahonije (Mahonia aquifolium), a s crvenim i ružičastim cvjetovima grmovi japanske dunjice (Chaenomeles japonica) i stabla crvenolisne šljive (Prunus cerasifera 'Nigra' i P. cerasifera 'Pissardii'). U travnju, za vrijeme cvjetanja, vrlo je dekorativno i obično Judino drvo (Cercis siliquastrum). Posebnost ove vrste su ružičasti cvjetovi u skupinama koji izbijaju izravno iz debla i grana. Kasnije u proljeće, obični divlji kesten (Aesculus hippocastanum), paulovnija (Paulownia tomentosa), cvjetni drijen (Cornus florida), vitka dojcija (Deutzia gracilis, slika 2), Vanhoutteova suručica (Spiraea $\times$ vanhouttei) i lovorvišnja (Prunus laurocerasus), samo su neke od vrsta koje cvjetovima uljepšavaju park. Krajem proljeća i početkom ljeta ističu se stabla obične i srcolisne katalpe (Catalpa

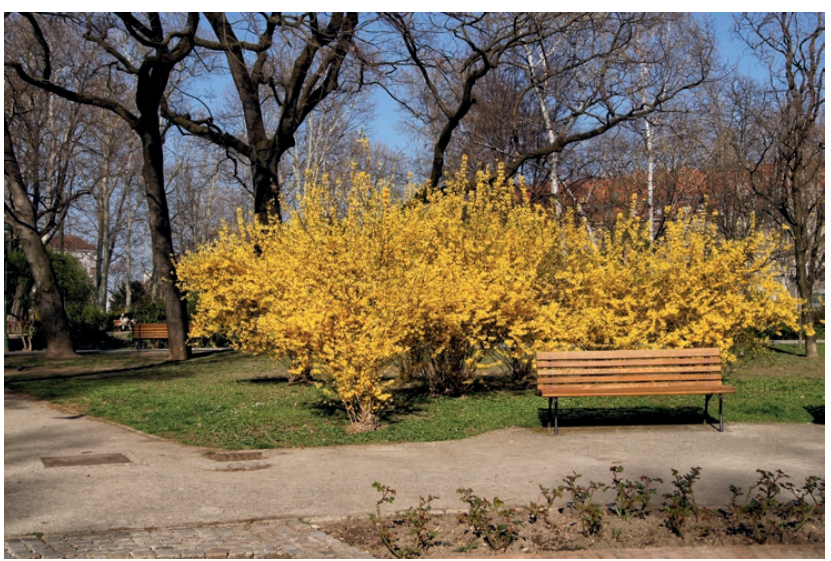

Slika 1. Forzicije (Forsythia $\times$ intermedia i F. suspensa). Figure 1 Forsythias (Forsythia $\times$ intermedia and $F$. suspensa). bignonioides i C. speciosa), grmovi sibirskoga drijena (Cornus alba) i pajasmina (Philadelphus coronarius) bijelih cvjetova, zatim grmovi kalikanta (Calycanthus floridus) crvenih cvjetova koji mirišu na jagode ili ananas te grmovi vajgelije (Weigela florida) ružičastih cvjetova. U lipnju svojim mirisnim cvjetovima pozornost privlače lipe (Tilia cordata, $T$. platyphyllos, T. tomentosa), a tijekom ljetnih mjeseci kontinuitet cvjetnog šarenila parku daju sirijske sljezolike ( $H i-$ biscus syriacus, $H$. syriacus 'Red Heart'), različite hortenzije (Hydrangea arborescens 'Grandiflora', H. macrophylla, H. quercifolia) i suručice (Spiraea japonica, S. japonica 'Albiflora', S. japonica 'Anthony Waterer'), tekoma (Campsis radicans) i japanska sofora (Styphnolobium japonicum). Neke biljke pak, poput hortenzija, sa svojim suhim sterilnim cvjetovima produžuju svoju estetsku vrijednost i na zimske mjesece.

Osim uresnih cvjetova, estetsku vrijednost pojedinim vrstama i kultivarima daju i plodovi. Tijekom ljeta i jeseni bijelim i crvenim plodovima park ukrašavaju grmovi sibirskoga (Cornus alba, C. alba, 'Elegantissima') i cvjetnoga drijena (Cornus florida), narančastim vatrenoga trna (Pyracantha coccinea), a plavkastocrnim obične mahonije ( $\mathrm{Ma}$ honia aquifolium). Tijekom zimskih mjeseci uresnim plodovima u parku se ističu stabla katalpa (Catalapa bignonioides i C. speciosa), božikovina (Ilex aquifolium), virdžinijskoga draguna (Diospyros virginiana), mandžurskoga plutnjaka (Phellodendron amurense), američkoga i maloazijskoga likvidambra (Liquidambar styraciflua i L. orientalis), gimnoklada (Gymnocladus dioicus) i hibridnih platana (Platanus $\times$ hispanica). Isto tako, kuglastim bijelim i grimiznovcrvenim plodovima nalik perlicama zimskom koloritu parka doprinose i niski grmovi grozdastoga i koraljnoga biserka (Symphoricarpos albus i S. orbiculatus).

S obzirom na područje prirodne rasprostranjenosti, na Trgu je determinirano 28 u Hrvatskoj autohtonih vrsta (dvije golosjemenjače i 26 kritosjemenjača). Prisutno je i šest vrsta koje su autohtone $\mathrm{u}$ drugim dijelovima Europe, ali ne $\mathrm{u}$

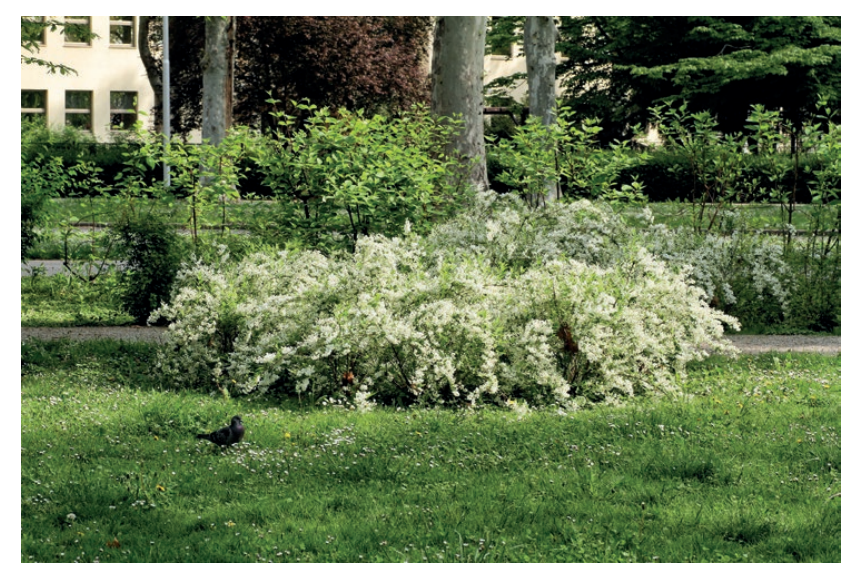

Slika 2. Vitka dojcija (Deutzia gracilis).

Figure 2 Japanese snow flower (Deutzia gracilis). 


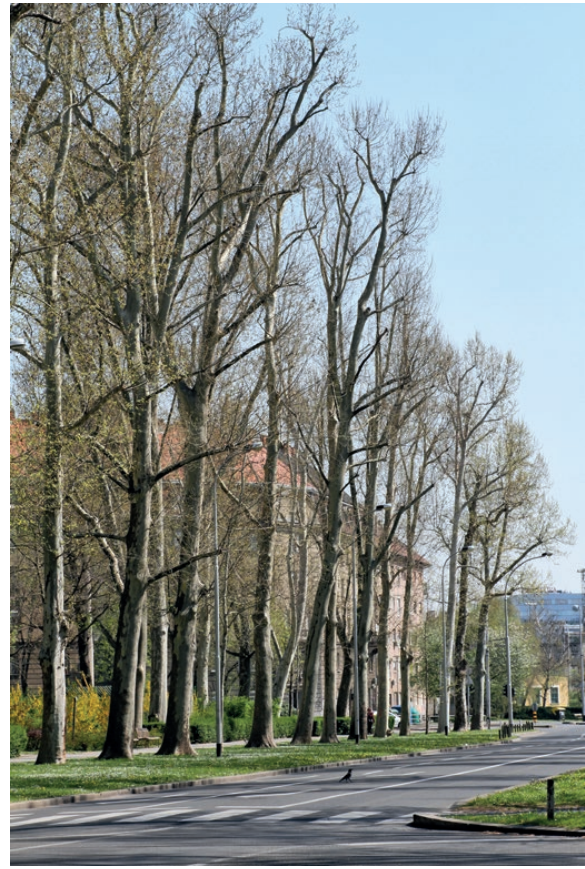

Slika 3. Hibridna platana (Platanus $\times$ hispanica).

Figure 3 London plane (Platanus $\times$ hispanica).

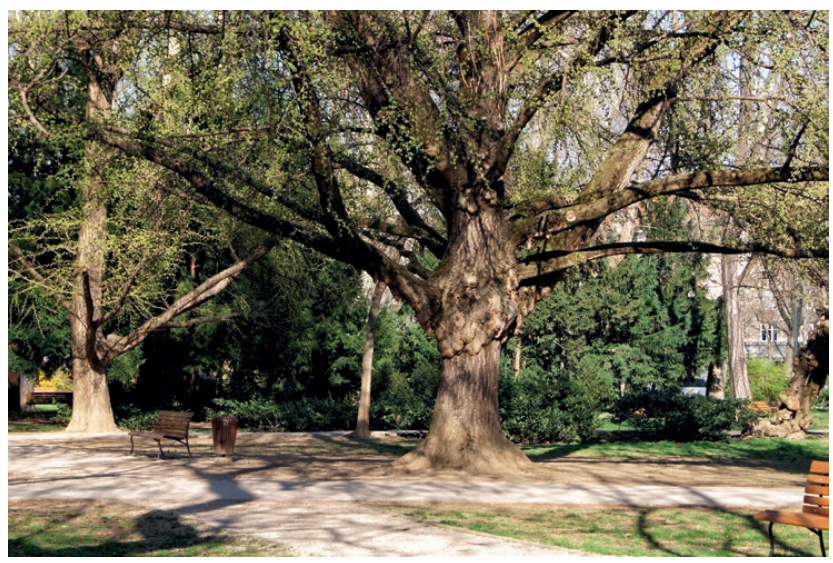

Slika 4. Ginko (Ginkgo biloba).

Figure 4 Maidenhair tree (Ginkgo biloba).

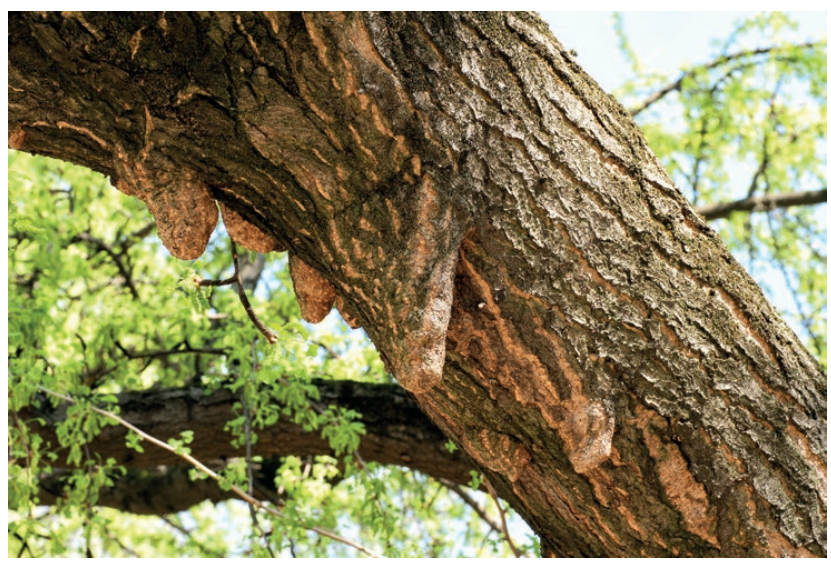

Slika 5. Zračno korijenje ginka.

Figure 5 Aerial roots of a ginkgo tree.
Hrvatskoj. Od ukupno 59 alohtonih vrsta, najveći dio pripada azijskim vrstama (jedna golosjemenjača i 31 kritosjemenjača), zatim sjevernoameričkim (četiri golosjemenjače i 17 kritosjemenjača), dok pet vrsta kritosjemenjača pripada euroazijskom području. Usporedimo li današnje stanje dendroflore s popisom iz 1995. godine, možemo zaključiti da se broj autohtonih vrsta povećao, a alohtonih smanjio. Sadnja autohtonih svojti za cilj ima očuvanje bioraznolikosti, pogotovo onih svojti koje su na svom prirodnom staništu ugrožene i zaštićene. Osim toga, autohtone svojte su prilagođene na lokalne uvjete staništa, što olakšava njihov uzgoj i održavanje.

Osim već spomenutih stabala ginka (Ginkgo biloba), hibridnih platana (Platanus $\times$ hispanica, slika 3), virdžinijskoga draguna (Diospyros virginiana), mandžurskoga plutnjaka (Phellodendron amurense), kao važan dio vizualnog identiteta ovog parka ističu se i stabla lipa (Tilia L.), javora (Acer L.) i hrastova (Quercus L.). Svakako je važno istaći muško stablo ginka impozantnih dimenzija koje se nalazi u središnjem dijelu južne cjeline parka, a koje pozornost privlači izraslinama zračnoga korijenja na granama i deblu (slika 4 i 5). Osim ginka, u južnom dijelu parka ističe se i zanimljivo stablo dudovca (Broussonetia papyrifera), izrazito deformiranog debla podbočenog potpornim stupovima (slika 6). Tu je i alpski vrt, zamišljen kao kamenjar s planinskim vrstama drveća, grmlja i zeljastih biljaka, ali nažalost prilično zarastao kupinom. Od autohtonih vrsta, u ovom dijelu parka zasađeno je nekoliko stabala običnoga graba (Carpinus betulus), obične breze (Betula pendula), tise (Taxus baccata), javora klena (Acer campestre) i bukve (Fagus sylvatica). Na sjevernom, manjem dijelu parka, uz dječje igralište ističu se stabla tulipanovca (Liriodendron tulipifera), američkog likvidambra (Liquidambar styraciflua), kultivar 'Fastigiata' Simonijeve topole (Populus simonii 'Fastigiata'), dok osnovno obilježje samom igralištu daju kultivari 'Umbraculifera' običnoga bagrema (Robinia pseudoacacia 'Umbraculifera'). U cvjetnom vrtu za odrasle dominira sta-

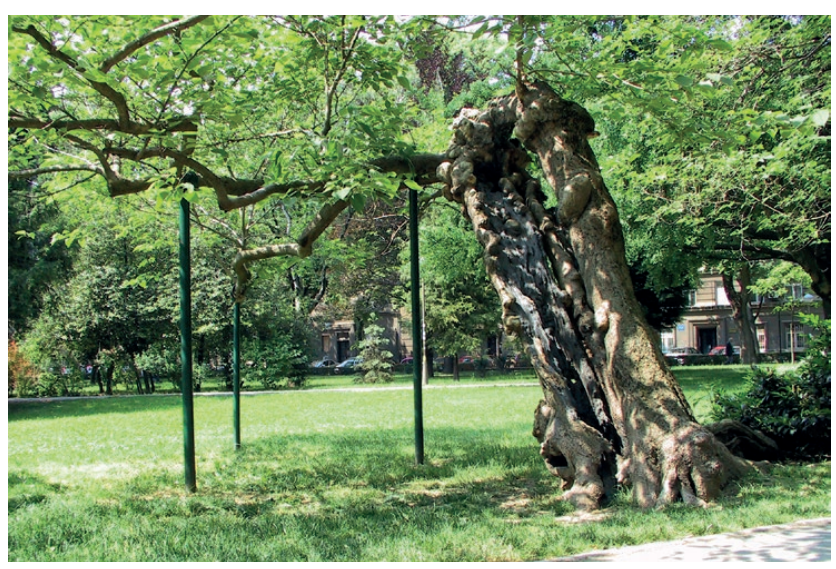

Slika 6. Dudovac (Broussonetia papyrifera).

Figure 6 Paper mulberry (Broussonetia papyrifera). 
blo parocije (Parrotia persica), a nakon obnove 2016. godine zasađene su razne cvjetajuće vrste grmova, kao što su velelisna i hrastolisna hortenzija (Hydrangea macrophylla i $H$. quercifolia), ružičasta vajgelija (Weigela florida), kineska hudika (Viburnum rhytidophyllum) i druge.

Hortikulturna vrijednost nekog prostora ne ovisi samo o biljkama, njihovom izgledu i rasporedu, već i o svim ostalim parkovnim elementima i sadržajima (Poljak i sur. 2011). Od bitnih elemenata i sadržaja za svaki park, tu su drvene klupe i koševi za smeće, zatim asfaltirane i šljunčane staze te rasvjetni stupovi. Od ostalih elemenata u parku se ističe fontana i bazen "Kozmički ciklus vode", izvorno djelo Josipa Seissela, nastalo 1935. godine te obnovljeno 2016. godine. Ono se nalazi u cvjetnom vrtu za odrasle, koji je jedan od tri djela sjeverne cjeline parka. Na dječje igralište 1939. godine postavljena je skulptura "Mali dječak", koju je izradio Emil Bohutinsky 1928. godine. Ova brončana figura dječaka na kamenom postolju u hrvatskoj modernoj skulpturi slovi za jedan od najboljih dječjih portreta. "Njegovateljica ruža" skulptura je poznatog hrvatskog akademskog kipara Frane Kršinića, izrađena 1953., a na današnju lokaciju postavljena je 1955. godine (Klindić 2019). Ona je u parku smještena na središnjem parternom vrtu sjeverne cjeline, nasuprot ulazu u Ministarstvo obrane, a ispred nje se nalazi ružičnjak koji dodatno naglašava njenu atraktivnost.

\section{ZAKLJUČAK}

\section{CONCLUSION}

Analizom trenutnog stanja dendroflore u parku dobiven je uvid u njezino bogatstvo i iznimnu dendrološku vrijednost, ali i potencijalne nedostatke i prostor za napredak. Velika raznolikost od čak 122 drvenaste svojte, kao i kulturno-povijesni značaj, dokaz su neprocjenjive vrijednosti ovog parka i temelji su njegovoga budućeg razvoja i očuvanja. Usporedba sa stanjem iz 1962. i 1995. godine daje dobar uvid u dinamiku i razvoj parka kroz vrijeme, kao i trendove u uređenju parkovnih prostora tada i danas. Suprotno modernim trendovima, treba raditi na reintrodukciji onih svojti koje su u parku bile prisutne u vrijeme njegovoga osnivanja, kao što su žuto drvo, patisa, snježna lopta i ljetni jorgovan. Budući da je sjeverni, manji dio parka obnovljen nedavnim projektima revitalizacije, pažnju treba pridati južnom dijelu, posebice alpskom vrtu, koji bi u svom punom sjaju još više pridonio vrijednosti i raznolikosti ovoga parka, a i upotpunio bi originalnu viziju projektanta iz 20. stoljeća. Park kralja Petra Krešimira IV. jedan je od starih parkova u Zagrebu koji je do danas ostao prepoznatljiv, a njegove kvalitete koje su dovele do statusa spomenika parkovne arhitekture moraju biti očuvane kako bi općekorisne funkcije koje park pruža ostale dostupne budućim generacijama.

\section{LITERATURA}

\section{REFERENCES}

- Anić, M., 1946: Dendrologija. Šumarski priručnik I. Zagreb, 475-582 str.

- Barišić, Z., 2002: Trg kralja Petra Krešimira IV. u Zagrebu Urbanističko-arhitektonska i perivojna geneza. Prostor 10, 1 (23): 77-91.

- Brickell, C. (ur.), 2003: RHS A-Z encyclopedia of garden plants, Vol. I-II. Dorling Kindersley, London.

- Brickell, C. D., C. Alexander, J. J. Cubey, J. C. David, M. H. A. Hoffman, A. C. Leslie, V. Malecot, W. L. A. Hetterscheid, X. Jin (ur.), 2016: International Code of Nomenclature for Cultivated Plants (ICNCP). Ninth Edition. Scripta Horticulturae Number 18, ISHS, 190 str.

- Brummitt, R. K., C. E. Powell, 1992: Authors of plant names. Royal Botanic Gardens, Kew, 732 str.

- Cronquist, A., 1981: An integrated system of classification of flowering plants. Columbia Univ. Press., New York, 1262 str.

- Dahlgren, R. M. T., H. T. Clifford, P. F. Yeo, 1985: The families of monocotyledons. Structure, evolution and taxonomy. Springer Verlag, Berlin, 520 str.

- Erhardt, W., E. Götz, N. Bödeker, S. Seybold, 2014: Zander. Handwörterbuch der Pflanzennamen. 19 Auflage. Eugen Ulmer KG, Stuttgart, 903 str.

- Farjon, A., 2010: A handbook of the world's conifers. Vol. I-II. Brill, Leiden.

- Herman, J., 1971: Šumarska dendrologija. Stanbiro, Zagreb, 470 str.

- Hillier, J. G., R. Lancaster (ur.), 2014: The Hillier Manual of Trees and Shrubs. Royal Horticultural Society, London, 565 str.

- Hoffman, M. H. A., 2016: List of names of woody plants. International standard ENA 2016-2020. Naktuinbouw, Roelofarendsveen, $1080 \mathrm{str}$.

- Idžojtić, M., 2005: Listopadno drveće i grmlje u zimskom razdoblju. Sveučilište u Zagrebu Šumarski fakultet, 256 str.

- Idžojtić, M., 2009: Dendrologija - List. Sveučilište u Zagrebu Šumarski fakultet, 904 str.

- Idžojtić, M., 2013: Dendrologija - Cvijet, češer, plod, sjeme. Sveučilište u Zagrebu Šumarski fakultet, 672 str.

- Idžojtić, M., 2019: Dendrology: Cones, Flowers, Fruits and Seeds. Elsevier - Academic Press, 800 str.

- International Plant Name Index. http://www.ipni.org./

- Jurković, M., B. Jurković, 1997: Prilog introdukciji i aklimatizaciji drvenastih egzota - listače u Zagrebačkim parkovima. Šumarski list 121 (5-6): 269-276.

- Karavla, J., 1962: Prilog opisu nalazišta egzota i nekih (forma) naših autohtonih vrsta na području nekih zagrebačkih parkova. Šumarski list 86 (7): 224-242.

- Kelly, J. (ur.), 2004: Hillier Gardener's Guide to Trees and Shrubs. David and Charles Book, Newton Abbot, 640 str.

- Klindić, I., 2019: "Njegovateljica ruža" Frane Kršinića na Trgu kralja Petra Krešimira IV. <https://licegrada.hr/njegovateljicaruza-frane-krsinica-na-trgu-kralja-petra-kresimira-iv/> (28. studeni 2019.)

- Kramer, K. U., P. S. Green (ur.), 1990: Pteridophytes and gymnosperms. U: Kubitzki, K. (Ed.), The families and genera of vas- 
cular plants. Vol I. Springer Verlag, Berlin, Heidelberg, New York, 404 str.

- Krüssmann, G., 1972: Handbuch der Nadelgeholze. Verlag Paul Parey, Berlin und Hamburg. 366 str.

- Krüssmann, G., 1976: Handbuch der Laubgeholze. Band I-III. Verlag Paul Parey, Berlin und Hamburg.

- Poljak, I., M. Idžojtić, M. Zebec, 2011: Dendroflora Zoološkoga vrta grada Zagreba. Šumarski list 135 (5-6): 269-279.

- Roloff, A., H. Weisgerber, U. M. Lang, B. Stimm (ur.), 19942019: Enzyklopadie der Holzgewachse: Handbuch und Atlas der Dendrologie. Wiley-VCH.

- Sopina, A., K. Radić, B. Bojanić Obad Šćitaroci, 2013: Perivoji u kontekstu urbanističkog razvoja grada Zagreba. Hrvatska akademija znanosti i umjetnosti, Zagreb, str. 165-177.

- Turk, D., 1995: Dendrološka i šumsko-uzgojna svojstva parka na Trgu kralja Krešimira IV u Zagrebu i smjernice za revitali- zaciju, Diplomski rad, Sveučilište u Zagrebu, Šumarski fakultet. 34 str.

- Turland, N. J., J. H. Wiersema, F. R. Barrie, W. Greuter, D. L. Hawksworth, P. S. Herendeen, S. Knapp, W.-H. Kusber, D.-Z. Li, K. Marhold, T. W. May, J. McNeill, A. M. Monro, J. Prado, M. J.Price, G. F. Smith (ur.), 2018: International Code of Nomenclature for algae, fungi, and plants (Shenzhen Code) adopted by the Nineteenth International Botanical Congress Shenzhen, China, July 2017. Regnum Vegetabile 159. Glashutten: Koeltz Botanical Books. https://www.iapt-taxon.org/nomen/main.php./

- Vidaković, M., 1982: Četinjače - morfologija i varijabilnost. JAZU \& Liber, Zagreb, 711 str.

- Vidaković, M., 1993: Četinjače - morfologija i varijabilnost. Grafički zavod Hrvatske \& Hrvatske šume, Zagreb, 744 str.

- *** Šumarska enciklopedija, Vol I-III, 1980-1987. JLZ „Miroslav Krleža“', Zagreb.

\section{SUMMARY}

The Park Kralj Petar Krešimir IV was constructed in the period from 1937 to 1938, and was the first modern city park in the country. The park was divided into two parts by a road. The southern part of the park was designed as a "more naturally" shaped space dominated by the central grassland, whereas the north, smaller unit, was divided into three parts: a flower garden for grown-ups, the central parterre, and a children's playground. Despite it being a large and important traffic junction nowadays, due to its lush vegetation it managed to preserve its intimate and meditative character used by many citizens to "escape" into the nature. In order to establish the current status of the woody plants on the territory of the Kralj Petar Krešimir IV Park in Zagreb, a dendrological analysis was performed and the current status of woody plants was compared to the status from 1962 and 1995. The plants were identified in the period from the summer of 2018 to the summer of 2019, and the paper includes an analysis of the following data: the number of individual taxa (species, subspecies, varieties, hybrids and cultivars), family affiliation, area, habitus and leaf duration, color of flowers, time of flowering, fruits and the number of autochthonous and allochthonous taxa. There were a total of 122 taxa recorded in the garden, distributed within 36 families: 83 species (six gymnosperms and 77 angiosperms), two subspecies (both angiosperms), 30 cultivars (one gymnosperm and 29 angiosperms), six hybrids (all angiosperms) and one variety (angiosperm). The genera with the most taxa are: Acer $\mathrm{L}$. - maples (9), Prunus L. - plums (6), Berberis L. - holly grapes and Lonicera L. - honeysuckles (5), and Cornus L. - dogwoods and Spiraea L. - bridal wreaths (4). The number of taxa increased by 40 compared to 1962, and by 29 compared to 1995 . There are 28 autochthonous taxa, and of the allochthonous ones, most are Asian and North American. According to leaf duration, the park is dominated by deciduous taxa, and as for the habitus, trees and shrubs are equally represented. The park is also home to numerous species and cultivars of flowering shrubs and trees which complement the area with their decorative flowers all year round. Despite the fact that in comparison with different arboreta and botanical gardens the park does not contain more significant woody taxa, nevertheless the trees of ginkgo, plane, common persimmon and Amur cork tree stand out, present in the park since its establishment and constituting an important segment of its visual identity. The Kralj Petar Krešimir IV Park is one of the rare urban parks in Zagreb which has remained well preserved to this day, and its qualities which had led to the status of a monument of park architecture must be preserved to make the public benefit provided by the park also available to future generations.

KEY WORDS: woody plants, dendrological analysis, trees and shrubs, horticulture, urban green spaces 